\title{
Mineral trioxide aggregate apical plug method for the treatment of nonvital immature permanent molars
}

\author{
Krasimir Hristov $^{1}$, Nataliya Gateva ${ }^{1}$, \\ Nadezhda Mitova ${ }^{1}$
}

1. Department Of Pediatric Dentistry, Faculty Of Dental Medicine, Medical University- Sofia;

\begin{abstract}
Apexification with calcium hydroxide as an apical barrier technique was the treatment of choice for immature necrotic teeth with incomplete roots and large apical foramina. However, long treatment time required for formation of apical barrier, multi-visit treatment sessions necessitating patient compliance and tooth fracture susceptibility are the disadvantages of this approach. Mineral trioxide aggregate is the most popular material for synthetic apical barriers alternative to traditional apexification treatment method with calcium hydroxide. This report demonstrates management of an immature maxillary first molar with necrotic pulp and apical pathosis which was successfully treated using one step apexification procedure with MTA for apical barrier formation. The follow - up period shows, that the use of MTA for apical plugging appears to be a valid treatment option for immature permanent teeth.
\end{abstract}

Keywords: MTA, immature permanent teeth, apexification

\section{Background}

Complete formation of the root and closure of the apical foramen continues for up to 3 years following eruption of the tooth (1). An immature permanent tooth having blunderbuss canal and open apex can be an endodontic challenge because of difficulty in obtaining an apical seal, and existing thin radicular walls which are susceptible to fracture (2). The purpose of the apexification therapy used in nonvital immature teeth is 
to induce the formation of a hard tissue barrier at the root apex or the completion of apical development (1). For years, apexification with calcium hydroxide as an apical barrier technique was the treatment of choice for immature necrotic teeth with incomplete roots and large apical foramina. However, long time for formation of apical barrier, multi-visit treatment sessions necessitating patient compliance and tooth fracture susceptibility are the disadvantages of this approach $(2,3)$.

For these reasons, one visit apexification has been suggested $(4,5)$. Mineral trioxide aggregate (MTA) is the most popular material for synthetic apical barriers alternative to traditional apexification treatment method with calcium hydroxide $(6,7)$. MTA combines biocompatibility and bacteriostatic action (8), with favourable sealing ability as root-end filling material $(9,10)$. The material consists of fine hydrophilic particles of tricalcium silicate, silicate oxide and tricalcium oxide (11). When MTA is mixed with sterile water, it forms a colloidal gel, and its setting time is 3 - 4 hours in the presence of moisture (12). Apical plugging with MTA is a simple and rapid technique that eliminates the need of successive intracanal dressing changes $(13,14)$.

This report demonstrates management of an immature maxillary first molar with necrotic pulp and apical pathosis which was successfully managed using one step apexification procedure with MTA for apical barrier formation.

\section{Case Description}

A 12-year-old boy without general health problems was referred to the Faculty of Dental Medicine Sofia, Bulgaria on September 14, 2016. The patient and his father reported that the right maxillary first permanent molar was treated endodontically 4 years ago due to caries complication. One month before the visit the tooth had become painful when chewing. The clinical examination revealed no facial asymmetry and no sinus tract in the area of the tooth. The tooth was tender on palpation in the periapical area and on percussion. Periapical radiographic examination revealed an immature permanent tooth with a wide open apex and a radiolucent area in the apical region of the palatal root. There were signs of inadequate root canal treatment with root filling material observed only in the coronal half of the roots (Figure 1a). Based on the clinical symptoms, the data from the clinical check up and the analysis of the x-rays the preliminary diagnosis was apical periodontitis of tooth 16 . The differential diagnosis was made with periapical cyst and was dismissed due to the dimensions of the periapical translucency and the medical history. A decision was reached that the tooth should be treated with apexification with Mineral trioxide aggregate (MTA) .

After the application of the rubber dam, the filling was removed using diamond bur, mounted on a highspeed handpiece. The pulp chamber was cleaned with the help of ultrasonic scaler and copious irrigation with water. Long ultrasonic tip (ET20, EndoSuccess, Acteon Equipment, France) was used to remove the root filling material. Approximate working length was established with both radiographic method and electronic apex locator (RAYPEX® 6 Apex Locator VDW GmbH Munich Germany). The palatal root canal was lightly mechanically cleaned using Hedstroem-files under irrigation with $2.0 \%$ sodium hypochlorite (Chloraxid 2,0\% I sodium hypochlorite CERKAMED Poland). The distal, the first and the second mesiobuccal canal were instrumented with rotary file SmartTrack 40.04 (Nikinc Dental B.V., Eindhoven, The Netherlands). The root canals were dried with sterile paper points and a calcium hydroxide paste (CALCIPAST, CERKAMED Poland) was placed into the root canals. Sterile cotton pellet was placed and the access cavity was closed with a temporary filling material (Cavit, 3M Espe, Seefeld, Germany). 

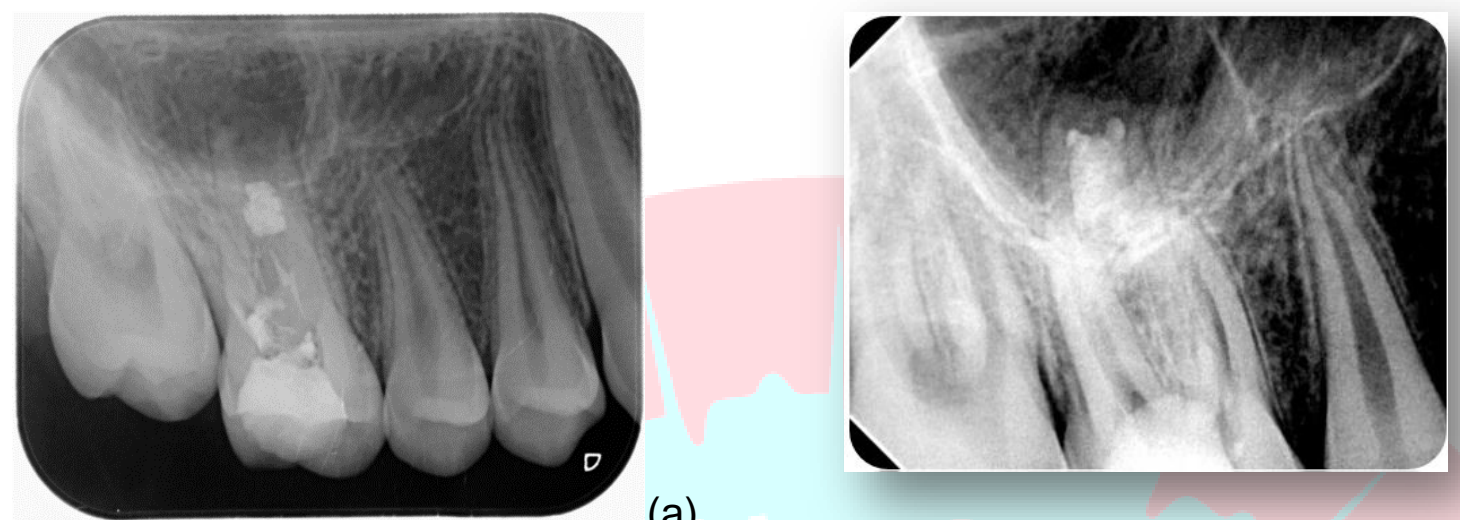

(a)

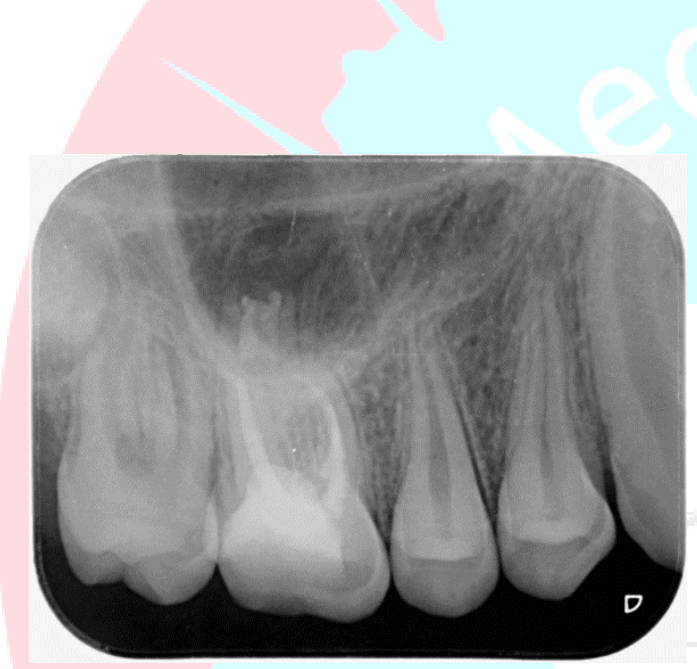

(c)

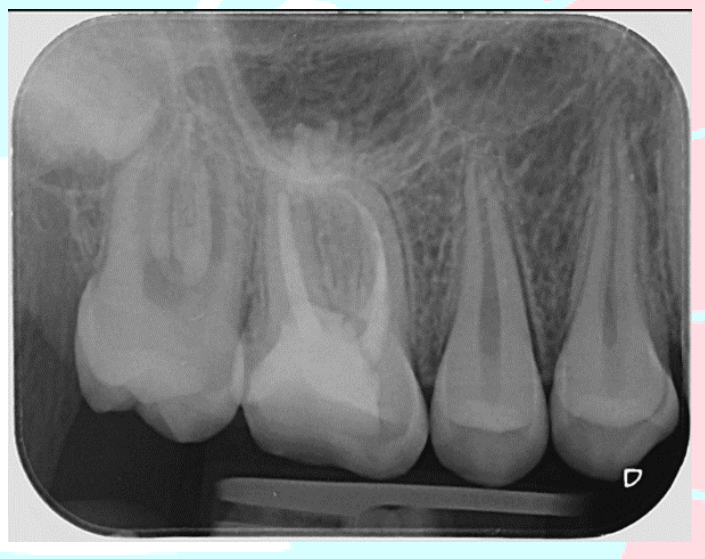

(d)

Figure 1. (a) A preoperative radiograph of maxillary right first molar with an open apex, (b) control of the MTA - plug, (c) 6 months follow-up, (d) Follow-up at 24 months

After 2-week interval the symptoms disappeared. The calcium hydroxide dressing was removed by instrumentation with Gentlefile Brush (MedicNRG, Kibbutz Afikim, Israel) and irrigation with $2.0 \% \mathrm{NaOCl}$ (Chloraxid 2,0\% / sodium hypochlorite CERKAMED Poland) and 17\% Ethylenediaminetetraacetic acid (EDTA; ENDO-SOLution CERKAMED Poland). The root canals were dried with sterile paper points. MTA (Bio-MTA+, Cerkamed, Poland) was mixed according to manufacturer's instructions and was placed with a small amalgam carrier to the canal orifice of the palatal root. The MTA mixture was adapted to the palatal canal walls with the help of a thick gutta-percha cone, measured $3 \mathrm{~mm}$ shorter than the working length. The other three canals were prepared and filled with calcium silicate composition: Well-Root ST ${ }^{\text {тM }}$ (Vericom, Knoxville, USA). The correct position of the apical plug and the root canal filling were confirmed with a periapical radiograph (Figure $1 \mathrm{~b}$ ). A wet cotton pellet was placed in contact with the setting cement and access cavity was sealed with a temporary filling. The temporary filling and cotton pellet were removed on the next visit and a probe was used to check the hardness of the MTA. Lateral condensation technique was 
used to fill the remaining part of the canal. Resin composite GC Gradia Direct (GC EUROPE, Belgium, Leuven) was used for the final restoration.

Normal function and absence of clinical symptoms were observed at 6 and 18 months follow-up period. The radiographic follow-up at 24 months showed a complete healing of the periapical radiolucency with regeneration of the periradicular tissue and new cement formation at end of the root (Figure 1c,d).

\section{Discussion}

Calcium hydroxide remains the most used remedy in the treatment of immature permanent teeth due to its low cost and ability to induce the formation of an apical barrier $(15,16)$. Cell migration, differentiation and production of organic matrix consisting of cementum or osteodentine determine the outcome of the apexification procedure (17). However, the placement of calcium hydroxide has potential disadvantages, including the long treatment period (3-21 months), unpredictability of apical closure, and difficulty in patient follow-up (18). Additionally, the long contact of the calcium hydroxide with collagen fibers of the root dentin reduces the fracture resistance of the tooth (5). During the waiting period, a leakage of the temporary filling material may lead to reinfection of the root canal system, thus decreasing the success rate ot the treatment (19). This can be avoided by performing a permanent treatment.

Presently, a novel approach suggests creating an one visit apical plug with MTA for treatment of non-vital immature permanent teeth (20). The material has less leakage with better antibacterial properties, high marginal adaptation and short setting time ( 4 hours) (21). Its biocompatibility and the ability to stimulate the production of interleukins and cytokines promote the formation of hard apical barrier (12). The tooth may be restored after 24 hours - the time needed for the material to set (5). This won't change the fracture resistance of the teeth, unlike the long term use of calcium hydroxide. Its property to set in moist environment makes MTA a suitable material for treatment of teeth with inflamed periapical lesions (14).

Temporary calcium hydroxide dressing is needed for disinfection of the root canals before creating apical plug with MTA (22). This is due to the fact that chemo-mechanical preparation alone does not completely remove the root canal microorganisms. In this case we used calcium hydroxide as a temporary dressing in the root canals for two weeks. There is no need the MTA to be pushed into apical tissues for the treatment to be successful. The control of the position and quality of the apical plug may be increased with the use of surgical microscope (19).

The use of MTA as an apical plug provides adequate seal against bacterial infiltration. This result is not affected from the thickness of the apical plug (23). It is important to remember that the thickness of the apical plug has an impact only on the displacement resistance (24). In the present case, it is about 4 to 5 $\mathrm{mm}$. In teeth with short root canals it is advised to reduce the thickness to $3 \mathrm{~mm}$ in order to leave space for filling of the remaining part of the canal.

In general, the outcome in this case report is similar to previously reported cases of successful MTA apical plug procedures in teeth with necrotic pulps and open apices $(7,19,22,25-27)$. In teeth with these clinical conditions, the outcome of conventional gutta-percha fillings would be uncertain, whereas MTA has the potential to provide predictable results (23). Two years radiographic and clinical follow-up revealed the supreme healing of the apical lesion and the regeneration of periradicular tissues. The clinical examination also confirmed the suitability of this method. 


\section{Conclusion}

Orthograde MTA apical plug might have success for managing necrotic immature permanent teeth. It is an effective method due to its reduced treatment time and appointments. This clinical case and its outcome is another prove for that.Future controlled and randomized studies on the use of MTA as apical plug would lend further support to this treatment option.

\section{References}

1. Simon S, Rilliard F, Berdal A, Machtou P. The use of mineral trioxide aggregate in one visit apexification treatment: A prospective study. Int Endod J 2007;40:186-197.

2. Andreasen J, Farik B, Munksgaard E. Long-term calcium hydroxide as a root canal dressing may increase risk of root fracture.. Dent Traumatol 2002;18:134-137.

3. Lin JC, Lu JX, Zeng Q, Zhao W, Li WQ, Ling JQ. Comparison of mineral trioxide aggregate and calcium hydroxide for apexification of immature permanent teeth: A systematic review and meta-analysis. J Formos Med Assoc 2016;115(7):523-530.

4. Morse D, O'Larnic J, Yesilsoy C. Apexification: review of the literature. Quintessence International 1990;21:589-598.

5. Holden D, Schwartz S, Kirkpatrick T, Schindler W. Clinical outcomes of artificial root-end barriers with mineral trioxide aggregate in teeth with immature apices. J Endod 2008;34:812817.

6. Torabinejad $\mathrm{M}$, Chiavian $\mathrm{N}$. Clinical application of mineral trioxide aggregate. J Endod 1993;25:197-205.

7. Shabahang S, Torabinejad $\mathrm{M}$. Treatment of theet with open apices using mineral trioxideaggregate. Practical Periodontics and Aesthetic Dentistry 2000;12:315-320.

8. Torabinejad M, Hong C, Pitt Ford T, Kettering J. Antibacterial effects of some root endfilling materials. J Endod 1995;21:403-406.

9. Torabinejad M, Smith $\mathrm{P}$, Kettering J, Pitt Ford $\mathrm{T}$. Comparative investigation of marginaladaptation of mineral trioxide aggregate and other commonly used root-end filling materials. J Endod 1995;21:295-299.

10. Xavier C, Weismann R, de Oliveira M, Demarco F, Pozza D. Root-end filling materials:apical microleakage and marginal adaptation. J Endod 2005;31:539-542.

11. Rafter M. Apexification: A review. Dent Traumatol 2005;21:1-8.

12. Tait $C$, Ricketts $D$, Higgins A. Weakened anterior roots-intraradicular rehabilitation. Br Dent J 198:609-617.

13. Kusgoz A, Yildirim T, Tanriver M, Yesilyurt C. Treatment of horizontal root fractures using MTA as apical plug: report of 3 cases. Oral Surg Oral Med Oral Pathol Oral Radiol Endod 2009;107:68-72.

14. Erdem A, Sepet E. Mineral trioxide aggregate for obturation of maxillary central incisors with necrotic pulp and open apices. Dent Traumatol 2008;24:38-41.

15. Trope M. Treatment of the immature tooth with a non-vital pulp and apical periodontitis. Dent Clin North Am 2010;54:313-324.

16. Stefopoulos S, Tzanetakis G, Kontakiotis E. Non-surgical retreatment of a failed apicoectomy without retrofilling using white mineral trioxide aggregate as an apical barrier. Braz Dent $\mathrm{J}$ 2012;23:167-171.

17. Ripamonti $U$, Reddi $A$. Tissue engineering, morphogenesis, and regeneration of the periodontal tissues by bone morphogenetic proteins. Crit Rev Oral Biol Med 1997;8(2):154-163. 
18. Metzger Z, Solomonov M, Mass E. Calcium hydroxide retention in wide root canals with flaring apices. Dent Traumatol 2001;17(2):86-92.

19. Giuliani V, Baccetti T, Pace R, Pagavino G. The use of MTA in teeth with necrotic pulps and open apices. Dent Traumatol 2002;18:217-221.

20. Lee $S$, Monsef M, Torabinejad M. Sealing ability of a mineral trioxide aggregate for repair of lateral root perforations. J Endod 1993;19:541-544.

21. Schwartz R, Mauger M, Clement D, Walker W3. Mineral trioxide aggregate: A new material for endodontics. J Am Dent Assoc 1999;130:967-975.

22. D'Arcangelo C, D'Amario M. Use of MTA for orthograde obturation of nonvital teeth with open apices: Report of two cases. Oral Surg Oral Med Oral Pathol Oral Radiol Endod 2007;104:98101.

23. de Leimburg M, Angeretti A, Ceruti P, Lendini M, Pasqualini D, Berutti E. MTA obturation ofpulpless teeth with open apices: bacterial leakage as detected by polymerase chain reaction assay. J Endod 2004;30:883-886.

24. Hachmeister D, Schindler G, Walker W, Thomas. The sealing ability and retentioncharacteristics of mineral trioxide aggregate in a model of apexification. $\mathrm{J}$ Endod 2002;28:386-390.

25. Maroto $M$, Barberia $E$, Planells $P$, Vera $V$. Treatment of a non-vital immature incisor with mineraltrioxide aggregate (MTA). Dental Traumatology 2003;19:217-221.

26. Torabinejad $M$, Chivian $\mathrm{N}$. Clinical applications of mineral trioxide aggregate. J Endod 1999;25:197-205.

27. Gunes B, Aydinbelge HA. Mineral trioxide aggregate apical plug method for the treatment of nonvital immature permanent maxillary incisors: Three case reports. J Conserv Dent 2012;15(1):73-76.

\section{Corresponding author:}

Krasimir Hristov,

Department of Pediatric Dentistry,

Faculty of Dental Medicine,

Medical University- Sofia,

1 Georgy Sofiyski Str

tel: +359 883411743

email: khristov87@gmail.com 